\title{
DNA PREPARATION FROM PLANT TISSUES WITH THE MAGNA PURE LC SYSTEM
}

\author{
Silke Hahnen ${ }^{1}$, Konstanze Hoffmann $^{2}$, Barbara RÜGer ${ }^{2}$, And Christoph Peterhänsel ${ }^{1}$ \\ ${ }^{1}$ Aachen University of Technology, Institute for Biology I, \\ Aachen, Germany \\ ${ }^{2}$ Roche Molecular Biochemicals, Penzberg, Germany
}

\begin{abstract}
Automated preparation of DNA from plants is difficult because of the rigid leaf structure and the high amount of mucleolytic activities in vacuoles. We established a protocol for DNA preparation from dried leaf samples of maize, tobacco, and periwinkle using the MagNA Pure LC system. The isolated templates can be used for PCR analysis with the Light Cycler instrument.
\end{abstract}

Biomed Eng Appl Basis Comm, 2002 (June); 14: 97-99.

\section{INTRODUCTION}

High-throughput analysis of DNA samples by PCR is now a common technique. For plants, these techniques are often used for gene mapping in large segregating populations [1] or for the identification of transgenic material in analyses on biological safety of genetically modified organisms [2]. Automatization of the DNA preparation is often hampered by the need to mechanically break the rigid cell walls of plants before DNA isolation. Furthermore, large amounts of nucleolytic products are liberated from the vacuole when plant cells are disrupted and the probability of DNA degradation during preparation is increased. When DNA is isolated from older leaves polysaccharides often copurify with the nucleic acids and interfere with many downstream applications. We evaluated the MagNA Pure LC in conjunction with the Light Cycler instrument to develop a system for the semi-automated analysis of large numbers of DNA samples by PCR.

Received: Dec. 20, 2001; Accepted: March 5, 2002 Correspondence: Christoph Peterhänsel,

Aachen University of Technology, Institute for Biology l, Worringer Weg 1, 52056 Aachen, Germany E-mail: cp@biol.rwth-aachen.de

\section{MATERIALS AND METHODS}

Leaf sections were harvested from approximately 10 week-old-plants of maize (Zea mays), tobacco (Nicotiana tabacum), and periwinkle (Cataranthus roseus). The leaf material was dried by lyophilization and stored at room temperature until further use.

For DNA preparation, $200 \mu \mathrm{l}$ of DNA I lysis buffer (MagNA Pure LC DNA Isolation Kit l)were added to $50 \mathrm{mg}$ of leaves (fresh weight) and homogenized with a rotor stator. Samples were centrifuged at $13.000 \times \mathrm{g}$ for 5' and supernatants were applied to MagNA Pure LC purification following the DNA I High Performance protocol.

In parallel, DNA was manually prepared from fresh leaf material following the CTAB-protocol with chloroform extraction as described before [3].

LightCycler amplification and detection with hybridization probes was done as described by the supplier using the LightCycler Fast Start DNA Master Hybridization Probes. Amplification conditions were $95^{\circ} \mathrm{C}$ for 10 minutes and 45 cycles, each cycle at 95 ${ }^{\circ} \mathrm{C}$ for 10 seconds, $56^{\circ} \mathrm{C}$ for 10 seconds and $72{ }^{\circ} \mathrm{C}$ for 20 seconds. For periwinkle, the annealing temperature was $58^{\circ} \mathrm{C}$. Oligonucleotides were purchased from $\mathrm{TiB}$ Molbiol (Berlin, Germany). For amplification of a GAPDH promoter fragment from maize primers were $5^{\circ}$ gga taa cgg acg gac gga $13^{\prime}$ and $5^{\prime}$ gca gcc ttt gct tta 


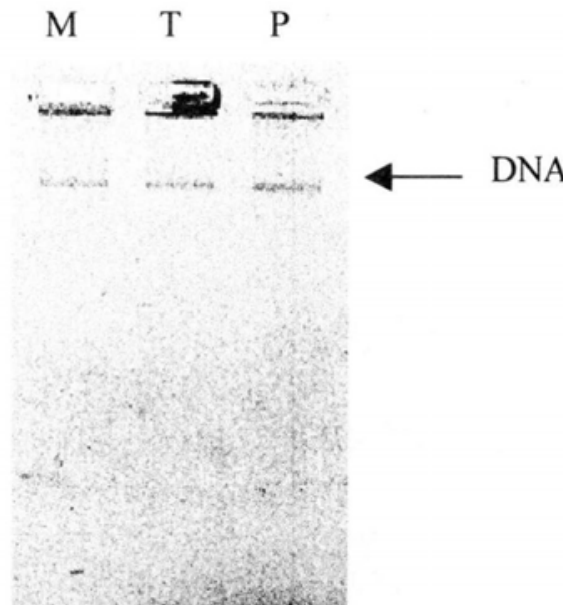

Fig. 1. Plant nucleic acids prepared with the MagNA Pure LC system. Nucleic acids were analysed on a $1 \%$ agarose gel in $1 \times$ TAE. $40 \mu$ of the DNA eluate were loaded in each lane. $M=$ maize, $T=$ tobacco, $P=$ periwinkle

tcc ttc at3' and hybridization probes were 5' ggc agc tca gct agc ttc gtt ccc 3' and 5' cca ctt ctt cgc tcc gtt cac cat c 3 '. For amplification of the ribonucleotide reductase promoter from tobacco primers were $5^{\prime} \mathrm{ttt}$ ctg acg tgc ttg aat atg gg 3' and 5' tta atg ctc tgt cat tgc taa cag t 3' and hybridization probes were 5' gcg gaa cct cca cac caa cct aa $3^{\prime}$ and $5^{\prime}$ ctt ctg get caa gct tca tca att $\operatorname{tg} 3$ '. For amplification of the tryptophan decarboxylase promoter region from periwinkle primers were 5' aga gtt tct tcc gcc gag gac 3' and 5' taa ata gcg gag ctt gca cca 3' and hybridization probes were 5' ata agc gca ttg gtc gac gaa tcg 3' and 5' cgc cga ttc tat att ttg agc cgg 3'.

\section{RESULTS AND DISCUSSION}

In order to establish DNA preparations from plants using the MagNA Pure LC system we used leaf material from three different plant species. Maize and tobacco were chosen because they represent the two important classes of higher plants (monocots and dicots, respectively). Periwinkle was additionally used because of its rigid leaf structure. Freeze-drying of leaf segments allowed the long-time storage of samples at room temperature. Dried leaves from all three species were easily homogenised in DNA I lysis buffer of the MagNA Pure LC DNA Isolation Kit I. Leaf debris and beads were separated by a short centrifugation to avoid clogging of tips during purification. The further purification followed the standard procedure also applied for animal tissues. Figure. 1 shows representative samples from the three different species after purification. In all lanes, high molecular weight DNA is clearly visible as a slowly migrating band near the slots. Similar results were obtained with leaf material from rapeseed (Bras-
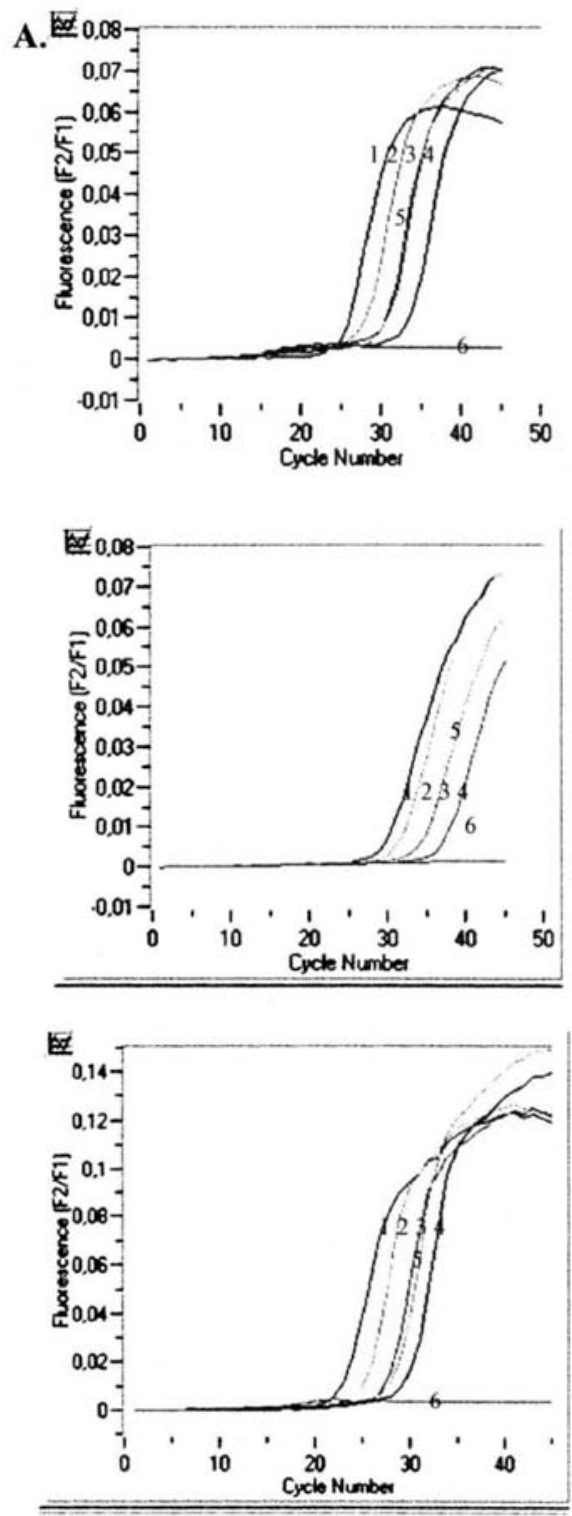

Fig. 2 Amplification curves with standard and MagNA Pure LC purified DNA. Shown is the relative fluorescence derived from the samples as indicated. $1=10 \mathrm{ng}$ template, $2=2.5 \mathrm{ng}$ template, $3=$ $0.5 \mathrm{ng}$ template, $4=0.1 \mathrm{ng}$ template, $5=2 \mu \mathrm{l}$ of DNA prepared with the MagNA Pure LC system, 6 $=$ negative control. A. $=$ maize, $B .=$ tobacco, C. $=$ periwinkle

sica napus) and sugarbeet (Beta vulgaris) (data not shown). Thus, the described protocol allows the automated preparation of intact DNA from dried leaf material.

To test whether the material is suitable for PCR amplification with the LightCycler instrument, the samples were compared to DNA that was manually prepared from fresh leaves using standard techniques. 
Single-copy genes were chosen to test amplification efficiency. Initially, amplification conditions were optimized by titration of annealing temperatures and $\mathrm{Mg}$ concentrations in the reaction mixture (data not shown). Figure 2 shows the amplification curves derived from the different templates. In all three cases, both types of DNA preparation were suitable for successful amplification. No products are visible in the negative control without template. As estimated from the standard, the DNA concentation in the MagNA Pure LC preparations was $0.25 \mathrm{ng}^{-1} \mathrm{l}^{-1}$ for all three preparations. Hence, approximately $25 \mathrm{ng}$ of DNA were isolated from 50 $\mathrm{mg}$ of sample allowing multiple amplifications from one preparation. Preliminary results with the recently introduced MagNA Pure DNA Isolation Kit for tissues show the yield can be further increased by a factor of ten. Thus, MagNA Pure LC system is a well suited system for high-throughput analyses of DNA samples from tissues of many plant species.

Note: This material has been previously published in the journal Biochemica by Hahnen S et al. 2001; 3: 1011. The permission from "Springer Publishers" has been received to republish this paper in this journal.

\section{REFERENCES}

1. Schulze-Lefert, P. (1995) Isolation of genes for resistance in plants. In: Ruven (ed.) Novel approaches to integrated pest management. CRC Press (Lewis Publishers), Boca Raton, FL

2. Vollenhofer, S., Burg, K., Schmidt, J., and Kroath, H. (1999) Genetically modified organisms in foodscreening and specific detection by polymerase chain reaction. Journal of Agricultural \& Food Chemistry. 47:5038-5043.

3. Stewart, C. N., and Via, L. E. (1993) A rapid CTAB DNA isolation technique useful for RAPD fingerprinting and other PCR applications. Biotechniques 14:748-750. 